\title{
A CRITICAL LOOK AT PREVALENCE ASSESSMENT OF DENTAL ABNORMALITIES AFTER CHEMOTHERAPY. CLINICAL RESEARCH
}

\author{
Anna Jodłowska', Grażyna Sobol-Milejska², Lidia Postek-Stefańska' ${ }^{1}$ \\ 'Department of Pediatric Dentistry, Medical University of Silesia, Katowice, Poland \\ ${ }^{2}$ Department of Paediatrics, Medical University of Silesia, Katowice, Poland
}

\begin{abstract}
INTRODUCTION: Dental abnormalities are relatively frequent among late complications of anticancer treatment received by patients at a young age. Available statistical reports are based on different research methods providing various results.

ОвјестіVEs: The purpose of the study was to assess the prevalence of agenesis and reduction in crown size in cancer survivors and healthy subjects with special attention to the age at which treatment was begun and therapy duration related to the developmental stage of the affected teeth.

MATERIAL AND METHODS: Cancer survivors and their healthy peers were examined clinically and radiographically towards an existence of hypodontia and changes in the dental crown size.

RESULTS: Cancer survivors had abnormalities examined in the prevalence of $62.16 \%$ and total number of 100 teeth disturbed. Significantly lower prevalence (13.51\%) and smaller number of teeth affected (10) were disclosed in the control group. After the affected teeth were divided into developmental groups, the mean age at the time of anticancer therapy varied noticeably and corresponded with expected time of early tooth development. Analysis revealed that $80 \%$ of survivors with hypodontia, $91.67 \%$ with microdontia, and $100 \%$ with teeth reduced in size received the therapy at the expected early development.

ConcLusions: The findings of the study showed a strong correlation between the age at the therapy and the expected time of odontogenesis of teeth affected in almost $98 \%$ of cases.
\end{abstract}

KEY wORDS: chemotherapy, tooth abnormalities, dental development.

J Stoma 2019; 72, 3: 95-105

DOI: https://doi.org/10.5114/jos.2019.87522

\section{INTRODUCTION}

More than 70\% of children with cancer survive the disease and, in majority of cases, require long-term observation because of the therapy-induced adverse effects [6]. Among late complications of anticancer treatment such as heart and hormonal disorders, neuro- and nephrotoxicity, growth impairment, and secondary cancers, dental abnormalities are relatively frequent $[5,8,16]$. The more information there is about the possibility and mechanisms of odontogenesis impairment, the earlier the radiological examination and orthodontic decisions are undertaken.

For at least three decades, statistical reports and experimental studies on animals have been performed to establish the prevalence and the kind of dental sequelae

JOURNAL OF STOMATOLOGY CZASOPISMO STOMATOLOGICZNE

AdDress For CORRespondence: Anna Jodłowska, PhD, Department of Pediatric Dentistry, Medical University of Silesia, Katowice, Pl. Traugutta 2, 41-800 Zabrze, Poland, e-mail: wega25@poczta.onet.pl 


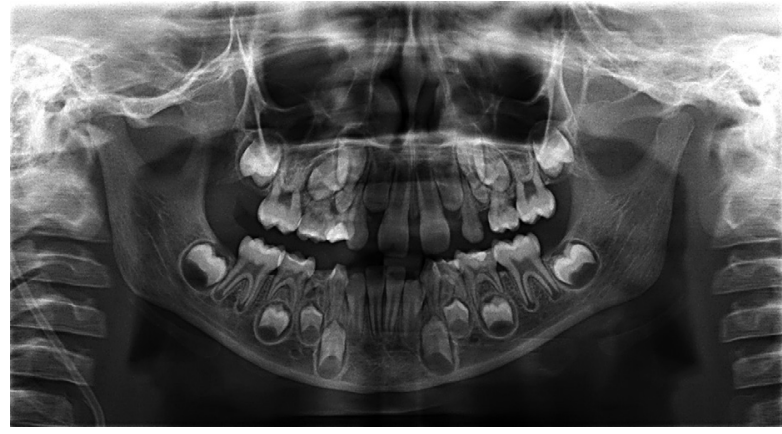

FIGURE 1. Panoramic radiograph in an 8-year-old male patient. Microdontal maxillary first premolars and mandibular first premolars reduced in size can be seen. Age at diagnosis: 15 months

in cancer survivors. Most of the authors used the Defect Index (DeI) established by Hölttä in 1978 to describe dental abnormalities after antineoplastic treatment [4, $10,14]$. Not all the research participants fulfil the criteria of honest evaluation, especially with regard to a longenough follow-up time after a harmful therapy. In numerous reported cases, the development of dental roots was not yet sufficient to assume an $\mathrm{R} / \mathrm{C}$ ratio suitable for DeI assessment. Additionally, root size variability is common in the healthy population, and a comparison to the rest of the fully developed dentition is a better choice. Moreover, DeI was also based on the evaluation of only microdontal "exceptionally small tooth" $[4,10]$. Reduction in size and microdontia, coexisting within the same group of teeth, are both evidence of the detrimental impact of anticancer therapy (Figure 1). Not taking into account this alteration can lead to underestimated results, as was suggested in the literature [10]. All the features should be determined after the particular parts of a tooth are completely developed with consideration of the possibility of post-treatment impact on tooth formation. In the literature, there is a paucity of results based on the detailed analysis of particular abnormalities related to the expected developmental stage of particular teeth and comparable assessment of the exact time of the harmful treatment [21]. A separate problem is the inclusion of third molars into the study, which is sometimes practiced [22]. Possible lack or small size of these teeth, as a result of the evolutional processes, makes a reliable analysis difficult. Many researchers exclude this group of teeth from the study. Similar problems may concern the lateral incisors or the second premolars because abnormalities in the development of these teeth are also relatively frequent in the healthy population.

Moreover, the detrimental effect on dental tissues, varying in accordance with the treatment time, if analysed in detail, creates the possibility of finding out more about the tooth germ formation.

\section{OBJECTIVES}

The study aimed to assess the prevalence of agenesis and reduction in crown size in cancer survivors and control subjects, and to determine the relationship between the occurrence of dental abnormalities and the time of the start of treatment and its duration against the developmental stage of the particular tooth affected.

\section{MATERIAL AND METHODS}

The research was approved by the Ethical Committee of the Medical University on February 25, 2013 and on November 29, 2016 (KNW/0022/KB1/15/I/13, $\mathrm{KNW} / 0022 / \mathrm{KB} 1 / 15 / \mathrm{II} / 16)$. According to study assumptions, the experimental group comprised cancer survivors aged 6-18 years, who met the following inclusion criteria: antineoplastic treatment completed before 10 years of patient's age and minimum two years prior to dental examination. The patients from the control group were randomly chosen from healthy children admitting to the Outpatient Developmental Age Clinic for a regular check-up or dental treatment. It was strictly controlled that the patients were at the same chronological age as those from the experimental group.

\section{EXPERIMENTAL GROUP}

Cancer survivors who received anticancer treatment in Upper Silesian Child Health Centre as children continue their appointments at the Oncological Outpatient Clinic until they are 18 years old. The patients who fulfilled the inclusion criteria were invited for research according to an examination protocol approved by the Bioethics Commission. Thirty-seven cancer survivors were admitted to the Outpatient Developmental Age Clinic of the Academic Centre of Dentistry after their guardians gave written consent for participation in the study. There were 21 girls (56.76\%) and 16 boys (43.24\%). The chronological age of patients at the time of dental examination was between 6 years and 17 years and 3 months, with an average of 9 years and 8 months. Twenty-eight patients had been treated for solid tumour, eight subjects for leukaemia, and in the last case Hodgkin lymphoma. All cancer survivors received chemotherapy. Twenty-six of them required surgical treatment and 12 required radiotherapy, with head irradiation in four cases. The dental investigation took place from 24 to 36 months after chemotherapy completion.

\section{CONTROL GROUP}

Children, who had been the patients of the Outpatient Developmental Age Clinic of the Academic Centre of Dentistry, after obtaining consent from their parents, 
were included in the study. Thirty-seven healthy subjects took part in the investigation: 20 girls (54.05\%) and 17 boys (45.95\%). They had non-contributory medical history and complying age criteria. The chronological age of patients qualified for the control group was between 6 years and 1 month and 17 years and 3 months, with an average of 9 years and 5 months.

\section{DENTAL EXAMINATION AND MEDICAL HISTORY ANALYSIS}

All the children accepted for the study underwent dental examination with special attention to the existence of dental abnormalities concerning hypodontia and changes in the size of the dental crown. If the anomaly was clinically observed, a photo image was taken. After conventional dental control, panoramic radiographs were obtained and assessment of the degree of tooth buds' development and the presence of dental anomalies was done. Panoramic radiographs were analysed by two examiners especially for agenesis, microdontia, and reduction in size that was not microdontia. The comparable assessment within the same group of teeth and determination of the type of dentition were also conducted.

The medical history of cancer survivors and healthy controls was collected from medical records. An analysis of medical records of oncological patients in terms of age at diagnosis, kind of disease, treatment duration, and therapy administered was conducted.

\section{STATISTICAL ANALYSIS}

The statistical analysis was carried out using Statistica Version 13.3 statistical analysis software. The values were presented as number $(N, n)$, percentage (\%), and months. Continuous variables were described as the mean, standard deviation (SD), minimum, and maximum. The $\chi^{2}$ test was applied, and the level of significance was determined. Yates' $\chi^{2}$ test was additionally done when required. In order to compare two different means within the same study sample, the non-parametric Mann-Whitney $U$ test was also used.

\section{RESULTS}

Among 37 members of the experimental group, $23(62.16 \%)$ cancer survivors had abnormalities examined in the total number of 100 teeth. Thirteen teeth were missing, 32 teeth were recognised as microdontal, and 55 were reduced in size. In the group of 37 control subjects, five (13.51\%) patients had changes observed: agenesis of eight tooth germs and two teeth reduced in crown size. Two patients had one second premolar missing each, the third had agenesis of two lateral incisors, the fourth had agenesis of four third molars, and the last one had

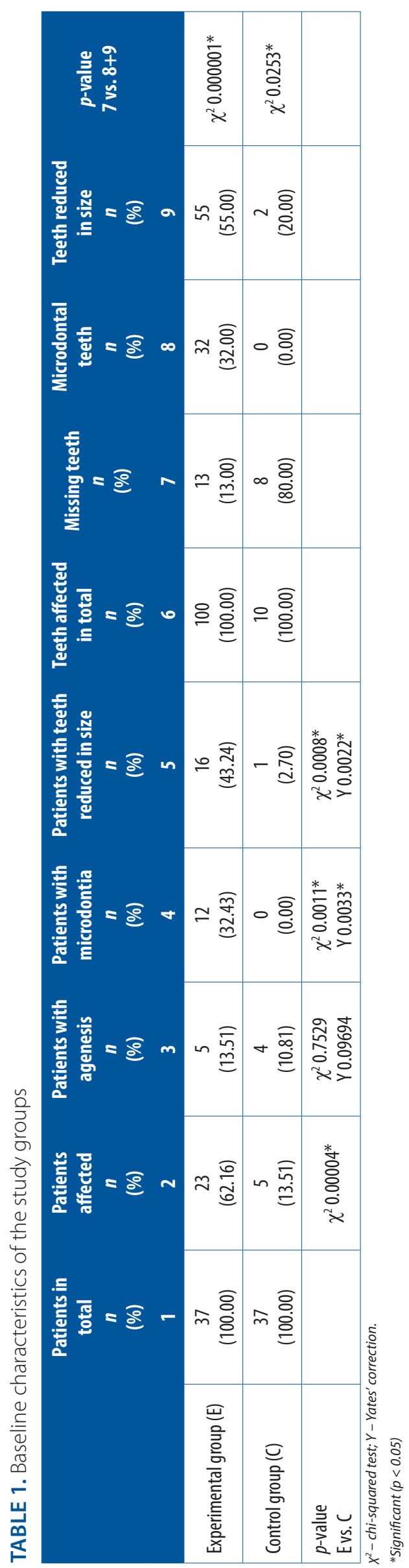


TABLE 2. Distribution of cancer survivors treated with chemotherapy according to the age of exposure

\begin{tabular}{|c|c|c|c|}
\hline Type of abnormality & $\begin{array}{c}\text { Survivors with age of exposure }<3 \text { years } \\
n(\%)\end{array}$ & $\begin{array}{c}\text { Survivors with age of exposure }>3 \text { years } \\
n(\%)\end{array}$ & $p$-value \\
\hline Total & $21(100.00)$ & $16(100.00)$ & 0.8144 \\
\hline Agenesis & $3(14.29)$ & $2(12.50)$ & 0.7429 \\
\hline Microdontia & $9(42.86)$ & $3(18.75)$ & 0.2311 \\
\hline Reduction in size & $14(66.67)$ & $2(12.50)$ & $0.0300^{*}$ \\
\hline Agenesis + microdontia or reduction in size & $2(9.52)$ & $1(6.25)$ & 0.8053 \\
\hline Microdontia + reduction in size & $17(80.95)$ & $4(25.00)$ & $0.0021^{*}$ \\
\hline Microdontia + reduction in size in 1 survivor & $6(28.57)$ & $1(6.25)$ & 0.1957 \\
\hline
\end{tabular}

*Significant $(p<0.05)$

TABLE 3. Age at chemotherapy in survivors with or without dental abnormalities in relation to the age at developmental periods

\begin{tabular}{|c|c|c|c|c|c|c|c|c|c|c|}
\hline & \multicolumn{3}{|c|}{$\begin{array}{l}\text { Age at start of treatment } \\
\text { (months) }\end{array}$} & \multicolumn{3}{|c|}{$\begin{array}{l}\text { Age at treatment } \\
\text { completion } \\
\text { (months) }\end{array}$} & \multicolumn{3}{|c|}{$\begin{array}{l}\text { Chemotherapy duration } \\
\text { (months) }\end{array}$} & \multirow[t]{2}{*}{$\begin{array}{l}\text { Expected age at start } \\
\text { of mineralisation } \\
\text { (months) }\end{array}$} \\
\hline & Min & Max & Mean \pm SD & Min & Max & Mean \pm SD & Min & Max & Mean \pm SD & \\
\hline $\begin{array}{l}\text { Survivors with lateral } \\
\text { incisors, premolars, and } \\
\text { second molars affected } \\
(n=20)\end{array}$ & 4 & 53 & $23.05 \pm 11.61$ & 18 & 62 & $38.10 \pm 14.56$ & 3 & 28 & $15.15 \pm 7.31$ & $10-36$ \\
\hline $\begin{array}{l}\text { Survivors with third } \\
\text { molars affected } \\
(n=3)\end{array}$ & 84 & 102 & $90.00 \pm 10.39$ & 101 & 192 & $141.33 \pm 46.37$ & 17 & 108 & $51.33 \pm 49.44$ & $84-120$ \\
\hline $\begin{array}{l}\text { Survivors without any } \\
\text { tooth abnormalities } \\
(n=14)\end{array}$ & 6 & 96 & $48.14 \pm 22.15$ & 27 & 101 & $62.14 \pm 21.79$ & 2 & 32 & $13.71 \pm 9.72$ & $\begin{array}{c}36-84 \\
\text { Developmental pause }\end{array}$ \\
\hline
\end{tabular}

two lateral incisors reduced in size. The number of patients with particular injuries in two groups differed significantly in terms of microdontia and reduction in size (Table 1).

The distribution of cancer survivors according to the age of exposure and type of dental abnormality is shown in Table 2. There were 21 patients treated with chemotherapy before they finished three years versus 16 participants treated at an older age. The number of survivors in the two age groups differed significantly when it came to reduction in size counted separately, and microdontia and reduction in size summarised. In the case of the remaining analysed features, the authors also noted a higher number of younger survivors affected compared to the older group, but the differences were not significant (Table 2).

The analysis of cancer survivors' medical history revealed that they started their antineoplastic treatment at the mean age of 3 years and 2 months (from the youngest aged 4 months to the oldest aged 8 years and 6 months). The duration of the anticancer therapy was 2 months minimum and 108 months maximum, with an average of 17.5 months. Based on the fact that formation of the third molars is significantly delayed compared to the rest of dentition, the cancer survivors were divided into three groups: a group with lateral incisors, premolars and second molars changed, a group with abnormal third molars, and a group with no tooth abnormalities. The mean age at the time of antineoplastic therapy varied noticeably and corresponded with the expected time of early tooth development, respectively, for each distinct group, whereas the patients with undisturbed dentition were treated from the mean age of 48.14 to 62.14 months, after the expected time of crown size determination of incisors, canines, premolars, and molars, and before the crowns of third molars were formed (Tables 3 and 4). Similar correlation is also seen in the majority of cases when the comparison of the patient's age at diagnosis and the expected time of early odontogenesis of abnormal teeth is conducted separately for each dental group. The age at the start of the therapy, in survivors with second premolars missing and lateral incisors reduced in size, exceptionally overlapped the late developmental period when the size of tooth is usually determined (Table 4). 

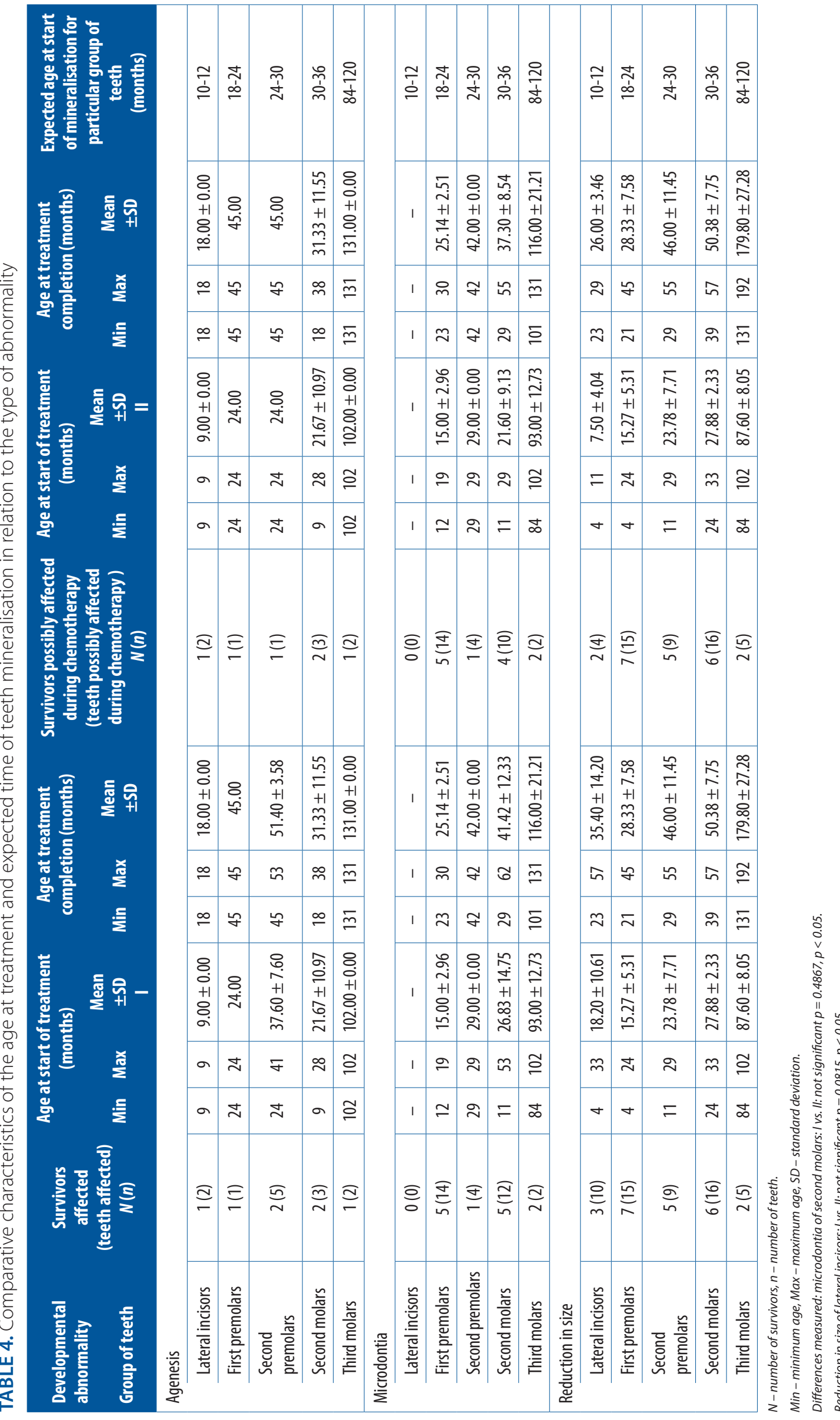
The results presented in Tables 5, 6, and 7 are based on the observation contained in Table 3 and 4 that the majority of patients with abnormal teeth were treated during the early developmental period of impaired teeth. The number of abnormal teeth with the supposable treatment background is 92 (92\%) of the total 100 changed teeth $(100 \%)$ in all survivors accepted to the study. It means that 2.49 abnormal teeth for each of the 37 (100\%) survivors. As a result of exclusion of the patients without abnormalities or with anomalies supposedly not being post-treatment effects, the number of survivors with changes that probably originated in antineoplastic treatment decreases to 21 subjects (56.76\%). In 21 patients with 94 abnormal teeth, 92 teeth with chemotherapy background gives a higher prevalence of $97.87 \%$ of ab- normal teeth and almost two-times higher number (4.38) of impaired teeth per patient (Table 5).

Careful analysis related to the kind of abnormality revealed that $80 \%$ of patients with missing teeth, $91.67 \%$ with microdontia, and $100 \%$ with teeth reduced in size received the antineoplastic therapy at the expected time of injured tooth development. Consequently, the chemotherapy background could be attributed to $69.23 \%$ of missing teeth, $93.75 \%$ cases of microdontia, and $89.10 \%$ of teeth with reduction in size. The number of abnormal teeth per patient after exclusion of cases without therapy origin increased only in terms of microdontia. This is in contrast to other analysed disturbances in which the number of teeth per patient decreased (Table 6).

TABLE 5. Distribution of teeth supposedly injured during chemotherapy in relation to total number of teeth affected

\begin{tabular}{|c|c|c|c|c|c|c|}
\hline & & $\begin{array}{c}\text { Number } \\
\text { of survivors } \\
n \\
(\%)\end{array}$ & $\begin{array}{c}\text { Teeth } \\
\text { affected } \\
n \\
(\%)\end{array}$ & $\begin{array}{c}\text { Teeth } \\
\text { affected per } \\
\text { patient } \\
n\end{array}$ & $\begin{array}{l}\text { Teeth with injury } \\
\text { supposedly induced by } \\
\text { chemotherapy } \\
n \\
(\%)\end{array}$ & $\begin{array}{l}\text { Teeth with injury } \\
\text { supposedly induced } \\
\text { by chemotherapy per } \\
\text { patient } \\
n\end{array}$ \\
\hline Survivors examined & I & $\begin{array}{c}37 \\
(100.00)\end{array}$ & $\begin{array}{c}100 \\
(100.00)\end{array}$ & 2.70 & $\begin{array}{c}92 \\
(92.00)\end{array}$ & 2.49 \\
\hline Survivors affected & $\|$ & $\begin{array}{c}23 \\
(62.16)\end{array}$ & $\begin{array}{c}100 \\
(100.00)\end{array}$ & 4.34 & $\begin{array}{c}92 \\
(92.00)\end{array}$ & 4.00 \\
\hline $\begin{array}{l}\text { Survivors affected with abnormalities } \\
\text { of chemotherapy background }\end{array}$ & III & $\begin{array}{c}21 \\
(56.76)\end{array}$ & $\begin{array}{c}94 \\
(100.00)\end{array}$ & 4.76 & $\begin{array}{c}92 \\
(97.87)\end{array}$ & 4.38 \\
\hline$p$-value & & $\begin{array}{l}\text { II vs. III } \\
0.8128\end{array}$ & $\begin{array}{l}\text { II vs. III } \\
0.0382^{*}\end{array}$ & $\begin{array}{c}\text { I vs. II } \\
0.0448^{*} \\
\text { || vs. III } 0.9506 \\
\text { I vs. III } \\
0.0382^{*}\end{array}$ & $\begin{array}{l}\text { I vs. III } \\
0.1275\end{array}$ & $\begin{array}{l}\text { Ivs. III } \\
0.0173^{*}\end{array}$ \\
\hline
\end{tabular}

*Significant $(p<0.05)$

TABLE 6. Distribution of cancer survivors and teeth affected in relation to the type of abnormality

\begin{tabular}{|c|c|c|c|c|c|c|c|c|}
\hline & I & II & III & IV & V & VI & VII & VIII \\
\hline $\begin{array}{l}\text { Type } \\
\text { of abnormality }\end{array}$ & $\begin{array}{c}\text { Patients } \\
\text { affected } \\
n \\
(\%)\end{array}$ & $\begin{array}{c}\text { Teeth } \\
\text { affected } \\
\text { in total } \\
n \\
(\%)\end{array}$ & $\begin{array}{c}\text { Teeth } \\
\text { affected } \\
\text { per patient } \\
n\end{array}$ & $\begin{array}{c}\text { Patients } \\
\text { with teeth } \\
\text { supposedly } \\
\text { injured during } \\
\text { chemotherapy } \\
n \\
(\%)\end{array}$ & $\begin{array}{c}\text { Teeth } \\
\text { affected } \\
\text { in total } \\
n\end{array}$ & $\begin{array}{l}\text { Teeth } \\
\text { affected } \\
\text { per } \\
\text { patient } \\
n\end{array}$ & $\begin{array}{l}\text { Teeth with injury } \\
\text { supposedly } \\
\text { induced by } \\
\text { chemotherapy } \\
n \\
(\%)\end{array}$ & $\begin{array}{c}\text { Teeth affected } \\
\text { per patient } \\
n\end{array}$ \\
\hline Agenesis & $\begin{array}{c}5 \\
(100.00)\end{array}$ & $\begin{array}{c}13 \\
(100.00)\end{array}$ & 2.60 & $\begin{array}{c}4 \\
(80.00) \\
\end{array}$ & 9 & 2.25 & $\begin{array}{c}9 \\
(69.23) \\
\end{array}$ & 2.25 \\
\hline Microdontia & $\begin{array}{c}12 \\
(100.00)\end{array}$ & $\begin{array}{c}32 \\
(100.00)\end{array}$ & 2.67 & $\begin{array}{c}11 \\
(91.67)\end{array}$ & 30 & 2.72 & $\begin{array}{c}30 \\
(93.75)\end{array}$ & 2.72 \\
\hline Reduction in size & $\begin{array}{c}16 \\
(100.00)\end{array}$ & $\begin{array}{c}55 \\
(100.00)\end{array}$ & 3.44 & $\begin{array}{c}16 \\
(100.00)\end{array}$ & 55 & 3.44 & $\begin{array}{c}49 \\
(89.10)\end{array}$ & 3.06 \\
\hline
\end{tabular}

Differences measured:

I vs. IV: not significant (agenesis $p=0.7604$; microdontia $p=0.8647$ ), $p<0.05$.

II vs. VII: not significant (agenesis $p=0.4977$; microdontia $p=0.8784$; reduction in size $p=0.4791$ ), $p<0.05$.

III vs. VIII: not significant (agenesis $p=0.8726$; microdontia $p=0.8452$; reduction in size $p=0.8570$ ), $p<0.05$. 
TABLE 7. Distribution of affected teeth according to the type of anomaly in all survivors and in survivors treated during odontogenesis of abnormal teeth

\begin{tabular}{|c|c|c|c|c|c|c|c|c|}
\hline \multirow[b]{2}{*}{$\begin{array}{l}\text { Group of teeth } \\
\text { affected }\end{array}$} & \multirow{2}{*}{$\begin{array}{c}\text { Teeth } \\
\text { affected } \\
n(\%)\end{array}$} & \multirow{2}{*}{$\begin{array}{c}\text { Teeth } \\
\text { supposedly } \\
\text { injured during } \\
\text { chemotherapy } \\
n(\%)\end{array}$} & \multicolumn{2}{|c|}{$\begin{array}{c}\text { Teeth with agenesis } \\
n(\%)\end{array}$} & \multicolumn{2}{|c|}{$\begin{array}{l}\text { Teeth with microdontia } \\
\qquad n(\%)\end{array}$} & \multicolumn{2}{|c|}{$\begin{array}{c}\text { Teeth reduced in size } \\
n(\%)\end{array}$} \\
\hline & & & In total & $\begin{array}{l}\text { Supposedly } \\
\text { injured during } \\
\text { chemotherapy }\end{array}$ & In total & $\begin{array}{l}\text { Supposedly } \\
\text { injured during } \\
\text { chemotherapy }\end{array}$ & In total & $\begin{array}{l}\text { Supposedly } \\
\text { injured during } \\
\text { chemotherapy }\end{array}$ \\
\hline Lateral incisors & $\begin{array}{c}12 \\
(100.00)\end{array}$ & $\begin{array}{c}6 \\
(50.00) \\
\end{array}$ & 2 & 2 & 0 & 0 & $\begin{array}{c}10 \\
(100.00)\end{array}$ & $\begin{array}{c}4 \\
(40.00) \\
\end{array}$ \\
\hline$p$-value & \multicolumn{2}{|c|}{$0.0184^{*}$} & & & & & \multicolumn{2}{|c|}{$0.0146^{*}$} \\
\hline First premolars & $\begin{array}{c}30 \\
(100.00)\end{array}$ & $\begin{array}{c}30 \\
(100.00)\end{array}$ & 1 & 1 & 14 & 14 & 15 & 15 \\
\hline \multicolumn{9}{|l|}{$p$-value } \\
\hline Second premolars & $\begin{array}{c}18 \\
(100.00)\end{array}$ & $\begin{array}{c}14 \\
(77.78) \\
\end{array}$ & $\begin{array}{c}5 \\
(100.00)\end{array}$ & $\begin{array}{c}1 \\
(20.00)\end{array}$ & 4 & 4 & 9 & 9 \\
\hline$p$-value & \multicolumn{2}{|c|}{0.1116} & \multicolumn{2}{|c|}{0.0528} & & & & \\
\hline Second molars & $\begin{array}{c}31 \\
(100.00)\end{array}$ & $\begin{array}{c}29 \\
(93.55)\end{array}$ & 3 & 3 & $\begin{array}{c}12 \\
(100.00)\end{array}$ & $\begin{array}{c}10 \\
(83.33)\end{array}$ & 16 & 16 \\
\hline$p$-value & \multicolumn{2}{|c|}{0.4722} & & & \multicolumn{2}{|c|}{0.4601} & & \\
\hline Third molars & $\begin{array}{c}9 \\
(100.00)\end{array}$ & $\begin{array}{c}9 \\
(100.00)\end{array}$ & 2 & 2 & 2 & 2 & 5 & 5 \\
\hline \multicolumn{9}{|l|}{$p$-value } \\
\hline Total & $\begin{array}{c}100 \\
(100.00)\end{array}$ & $\begin{array}{c}88 \\
(88.00)\end{array}$ & $\begin{array}{c}13 \\
(100.00)\end{array}$ & $\begin{array}{c}9 \\
(69.23)\end{array}$ & $\begin{array}{c}32 \\
(100.00)\end{array}$ & $\begin{array}{c}30 \\
(93.75) \\
\end{array}$ & $\begin{array}{c}55 \\
(100.00)\end{array}$ & $\begin{array}{c}49 \\
(89.09) \\
\end{array}$ \\
\hline$p$-value & \multicolumn{2}{|c|}{0.3814} & \multicolumn{2}{|r|}{0.3937} & \multicolumn{2}{|c|}{0.7994} & \multicolumn{2}{|c|}{0.5562} \\
\hline
\end{tabular}

Analysis related to the particular group of injured teeth showed that $50 \%$ of lateral incisors, $100 \%$ of first premolars, $77.78 \%$ of second premolars, $93.55 \%$ of second molars, and $100 \%$ of third molars might have been injured at the time of antineoplastic treatment. A thorough analysis revealed that the above-indicated differences concerned the agenesis of second premolars, microdontia of second molars, and reduction in crown size of lateral incisors (Table 7).

\section{DISCUSSION}

DeI or Modified Dental Defect Index (MDDI) was often used in previous studies, and it gave some information about the degree of damage to dental development $[4,10,11,14]$. However, the latency period was not always appropriate to show all of the post-treatment disturbances. Moreover, the value of DeI is strongly age dependent, both at diagnosis and at dental examination. To establish the changes in the tooth size, the development of half of the crown height is sufficient. When it comes to root disturbances, full development of the whole dentition is needed during dental investigation. In the literature there is research undertaken one year after therapy completion [14]. Gawade et al. [7, 11] suggest a mini- mum two-year follow-up after finishing the anticancer treatment. Cubukcu et al. [4] also used DeI to determine the total injury to permanent teeth, but they controlled the subjects in remission at least for five years. Usually the range of the examination age in the study group does not allow us to measure the values related to all of the developmental anomalies that could happen in permanent teeth. There is a need to prolong the observation or limit the evaluation to a few well-known factors and their reciprocal relationship. Different toxic agents and their various doses used in the therapy, and different duration of the anticancer treatment in combination with various dental ages, make the comparative assessment more complicated and prone to misinterpretation. Therefore, different results of DeI values can be found in the literature. Cubukcu et al. [4] noted DeI variation from 0 to 49 (mean $10.8 \pm 11.2$ ), Krasuska-Sławińska et al. [14] $12.48 \pm 13.16$, Hölttä et al. [10] - 4-34 (mean $15.3 \pm 9.3$ ), and Wilberg et al. [24] - 13.7. The inclusion criteria in the current study allowed for reliable assessment of examined abnormalities, and the tooth agenesis was estimated after the expected time of germ mineralisation.

Microdontia is classified as the presence of halfsized or smaller tooth crown. Microdontia, in its precise meaning, is most often a subject of assessment of its prevalence $[9-11,21]$. However, sometimes the infor- 
mation on the degree of crown damage is not indicated in the study or is described as tooth size smaller than average $[1,17,18,22]$. The reduction in crown size is very common if microdontia of another one or two teeth that originated in the same developmental period is recognised. It obviously indicates that all the alterations are caused by the same simultaneously occurring environmental factor. In such a situation, even small crown abnormality indicates a toxic impact of anticancer treatment. Therefore, the authors of the current study conducted a comparable assessment of tooth size within the same class of teeth following determination of the anomaly. When it comes to lateral incisors and third molars, some researchers do not take into account the disturbances concerning these teeth because of their higher prevalence in a healthy population $[11,12]$. In fact, hypodontia of at least one of the third molars was noted in 35\% and microdontia of lateral incisors in $1.7 \%$ of the general population $[9,12]$. What is more, for comparative prevalence assessment in healthy and treated subjects, the inclusion of these teeth seems to be necessary. Hölttä et al. [9] diagnosed high prevalence of 52\% of stem cells recipients with abnormal third molars. Cubukcu et al. [4] involved lateral incisors into the study, but recommended caution in drawing conclusions. Usually, all of the teeth mineralised after birth are included in investigation $[1,9,20]$. By paying special attention to patient's age during the antineoplastic treatment, one can predict the possible reason for the anomaly.

Table 1 shows the significant difference in prevalence of dental disturbances without taking into account the age factor. $62.16 \%$ of survivors versus $13.51 \%$ of healthy patients had abnormalities (Yates' $\chi^{2}$ test: $p=0.00004, p<0.05)$. Prior study has shown revised disturbances in patients after stem cell transplantation with a prevalence of $51 \%$ and $69 \%$, respectively, with third molars excluded and included [9]. Other researchers revealed $55.6 \%$ and $62.29 \%$ of patients with at least one abnormality $[11,22]$. The results are comparable. In the experimental group microdontia was recognised with a prevalence of $32.43 \%$, and reduction in size $43.24 \%$. In total, both abnormalities were diagnosed in $56.75 \%$ of survivors. When the reduction in size is considered as a result of cytotoxic damage, the prevalence concerning to smaller teeth appears to be higher than noted in the literature. In one study $26.7 \%$ and $13.3 \%$ of patients treated for leukaemia had upper and lower teeth affected, respectively, and patients suffering from solid tumours had upper and lower teeth damaged in a prevalence of $16.2 \%$ and $2.7 \%$, respectively [17]. In other research $19.3 \%$ of survivors versus $0 \%$ of controls had diagnosed premolars and molars disturbed [21]. The prevalence of $3 \%, 5.2 \%, 13.5 \%, 18 \%, 28 \%, 30.6 \%$, $36.06 \%$, and $38 \%$ was also noted $[1,4,11,12,18,20,22$, 24]. Hölttä et al. [10] divided all the patients into TBI and non-TBI group and detected relatively high prevalence of $80 \%$ and $85.7 \%$ with abnormalities, respectively.
Current analysis revealed no microdontia and a relatively small number of teeth reduced in size in the control group in comparison with cancer survivors -2 versus 55. A significantly more frequent anomaly in the healthy population was tooth agenesis $\left(\chi^{2}\right.$ test: $p=0.0253$, $p<0.05)$ as opposed to alterations after chemotherapy - smaller teeth were significantly more frequent compared to agenesis ( $\chi^{2}$ test: $p=0.000001, p<0.05$ ). Missing teeth made up $13 \%$ of all disturbed germs in survivors versus $80 \%$ in the control group. Despite the small number of healthy participants in the current study, it is obvious that hypodontia is the most frequent abnormality in the general population. However, agenesis in the prevalence of $13.51 \%$ of treated patients was higher in comparison with healthy controls, at $10.81 \%$. Similarly to the observations of Avsar et al. [1], the difference was not significant. Pedersen et al. [21] noted hypodontia in $9.3 \%$ of survivors and $4.1 \%$ in a control group. Previous studies have shown agenesis in 5\%, 7\%, $16.2 \%$, $17 \%, 19.8 \%, 20.4 \%, 31 \%, 31.14 \%$, and $44 \%$ of the entire group of cancer survivors $[1,4,9,11,12,18,20,22,24]$. The wide variation of values was probably caused by different contributing factors with a predominant role of the variety of inclusion criteria.

Young age at diagnosis of cancer is usually raised as the most important risk factor for late adverse dental effects of antineoplastic treatment. Microdontia and hypodontia were recognised with a prevalence of $31.6 \%$ and $10.5 \%$, respectively, in children receiving chemotherapy before they were three years old, and with a prevalence of $6.8 \%$ and $6.8 \%$, respectively, in the group of older participants [21]. Maguire et al. [17] found microdontia in $38 \%$ of survivors who had treatment at or earlier than three years of age. Kang et al. [11] revealed that the prevalence of tooth agenesis and microdontia decreases with the patient's age at the time of therapy. The authors of the current research noted a prevalence of $42.86 \%$ regarding microdontia and $66.67 \%$ relating to teeth reduced in size in survivors receiving chemotherapy before they were three years old. When analysing all of the smaller teeth, the prevalence of the anomaly increased significantly to $80.95 \%$ of the younger group versus $25 \%$ in the children exposed after they were three years old $(p=0.0021, p<0.05)$. All of the types of dental abnormalities in younger participants listed in Table 2 exist in higher numbers in comparison with older subjects. The lack of significant differences resulted from changes concerning third molars developing at a later age. All of the abnormal third molars found in the study might have been injured during chemotherapy (Tables 3 and 4 ). The authors agree with the opinion that young age at diagnosis remains the most prevalent risk factor for abnormal tooth development. These results are similar to those found in another study in which the microdontia was estimated with a prevalence of $75 \%$ in individuals aged less than 3.0,60\% for patients between 3.1 and 5.0 years of age, and $13 \%$ for the group older than 
5 years [9]. In contrast, some investigators found no significant relationship between the tooth impairment and age of therapy administration. The wide age group, small cohort, and lack of analysis dependent on the treatment age have been suggested as the reasons for the results observed $[1,20,22]$.

Distinct statistical values can be determined when the age at cytotoxic treatment is compared to expected time of mineralisation of particular teeth changed. The third molars start to mineralise at a later age in comparison with the remaining teeth. Based on the differences in the developmental period, the survivors were divided into three groups: patients with lateral incisors, premolars, and second molars changed; patients with third molars damaged; and participants without any tooth abnormalities (Table 3). On the premise that the toxic agent responsible for tooth crown injury should affect the germ before the mineralisation starts, the mean age at diagnosis in the current study overlaps the expected time before apposition of dental tissues. Interestingly, the patients who were treated during the "developmental pause" between the start of mineralisation of the tooth groups analysed had no teeth disturbed. Depending on the kind of abnormality, a correlation was revealed between the patient's age during treatment and the vulnerable period of development in relation to individual groups of teeth (Table 4). The patients with almost all groups of teeth damaged had had chemotherapy administered before the start of tooth germ mineralisation. Exceptionally, in the cases of second premolar agenesis and reduction in size of lateral incisors, the mean age at diagnosis exceeded the onset of dental tissue deposition. This suggests another background of abnormalities and is in agreement with the fact that the second premolars missing, and smaller lateral incisors are relatively often diagnosed in the general population. Proc et al. [22] did not find a relationship between the agenesis in general and patient's age at the start of therapy. Based on the observations listed in Table 3 and the first part of Table 4, the authors excluded participants having teeth without a supposed chemotherapy background (second part of Table 4). The mean age at diagnosis in the survivors with second premolar agenesis, microdontal second molars, and lateral incisors reduced in size decreased. The results concerning two controversial groups of teeth have changed, and the age at diagnosis preceded the mineralisation of mentioned teeth. Some authors reported that microdontal teeth were found in patients who started their therapy before they were 42 months of age. Children aged between 43 and 61 months had no abnormalities, and patients treated at the age older than 61 months presented with disturbed third molars [22].

Prior studies have reported a correlation between the treatment duration and the occurrence of disturbed odontogenesis, not found in the current paper (group average - 17.5 months) (Table 3). Subjects treated for leukaemia are likely to exhibit more severe dental impair- ment due to longer drug administration [17]. It seems to be obvious that the longer the duration of toxic therapy, the greater the expected tooth damage. However, the existence of many additional factors influencing dental development such as the kind of treatment protocol, age at diagnosis, and supplementary radiotherapy can impair reliable assessment. In the present study, in a patient with diagnosis of teratoma who received four-month chemotherapy, three microdontal first premolars were recognised. In contrast, a girl diagnosed with leukaemia at the age of six months was treated for 29 months and has no dental abnormalities. The two described patients had no radiotherapy administered. An additional problem is the evaluation of the separate influence of chemotherapy and radiotherapy administered together. The information about the area of irradiation is sometimes not included in the study. In the analysed group, only four patients received head radiotherapy, and three of them had only third molars disturbed due to late age of treatment. Owing to the homogeneity of the group, with regard to the kind of treatment, and taking into account that consanguineous features were evaluated, the results seem to reliable. Hölttä et al. observed no differences between groups treated with or without total body irradiation [10].

The above presented results were estimated without taking into account the age factor and its relationship with dental development of particular teeth. Third molars start to mineralise in children aged seven years. The present study demonstrated nine third molars missing or smaller in three patients treated since they were 7,7 , and 8.5 years old, respectively. No abnormalities concerning third molars were found in survivors treated at a younger age. Following the exclusion of survivors who had been treated not at the time of odontogenesis, the number of teeth affected decreased. As a result of the subsequent exclusion of abnormalities not corresponding with the treatment time, it appeared that in children treated during the sensitive period of tooth development, $97.87 \%$ of teeth might have had the injury caused by antineoplastic agents. This makes up $92 \%$ of the total number of abnormal teeth found in the study (Table 5). The authors of the paper agree with the opinion that post-treatment deviations would be expected in all of the patients who received the chemotherapy during tooth development [22]. The survivors presenting undisturbed dentition were mostly treated for cancer at an older age, except for two cases with remarkably short chemotherapy administration and one patient diagnosed with leukaemia at the age of six months. After the patients and teeth without supposed chemotherapy background were excluded, the number of abnormalities with hypothetical chemotherapy origin increased significantly from 2.49 per patient in the study to 4.38 per patient affected. Pedersen et al. [21], who included maximally half-sized teeth in the study, found $88 \mathrm{ab}$ normal premolars and second molars in 29 patients, i.e. 
3.03 teeth per subject. Hölttä et al. [9] reported 4.1 and 1.1 missing teeth per patient (third molars included), respectively, in TBI and non-TBI groups of paediatric stem cell transplantation recipients. The same study demonstrated the teeth missing per patient with mean number $4.7,4.9$, and 0.9 in recipients aged maximally 3 , 3.1-5, and more than 5, respectively [9].

The number of teeth affected per patient in relation to the type of abnormality increased not significantly only in the case of microdontia after exclusion of survivors and teeth without therapy background. The authors noted the highest prevalence of $93.75 \%$ among microdontal teeth with chemotherapy background considered (Table 6). Maguire et al. demonstrated $84 \%$ of the total number of microdontal teeth in patients with therapy administered in the period of crown formation [17]. After exclusion of teeth without therapy aetiology, the number of missing teeth and teeth reduced in size per patient decreased not significantly. It has already been mentioned that tooth agenesis and teeth smaller than normal appear in the healthy population.

Prior study has shown that the second premolars were the most frequently affected teeth in both survivors and controls $-82.1 \%$ and $88.9 \%$ of disturbed teeth, respectively. The distribution of microdontia and hypodontia in 150 survivors was 32 and 22 affected second premolars, respectively. Thirty-two second molars and 29 first premolars were after injured teeth in survivors versus only two missing second molars in controls [21]. The second premolar was the most common missing tooth, and the maxillary second premolar followed by maxillary second molar exhibiting microdontia in another study [11]. The next research revealed that the most prevalent affected teeth were second premolars followed by second molars in relation to both hypodontia and microdontia [22]. Conversely, in the current study the largest group of teeth affected were second molars and first premolars. All of the first premolars and $93.55 \%$ of the second molars are likely to present the treatment background of impairment. A less prevalent tooth disturbed is the second premolar, with $77.78 \%$ of affected teeth probably injured during chemotherapy. Following exclusion of abnormalities in patients treated beyond the time of the early odontogenesis of analysed teeth, it appeared that the number of affected teeth decreased with reference to agenesis of the second premolars, microdontia of second molars, and reduction in size of lateral incisors (significant: $p=0.0146, p<0.05$ ). Similar impairment of these teeth is found in the general population. The remaining abnormalities are rare in healthy subjects. The survivors who exhibit these defects were treated during odontogenesis of injured teeth (Table 7).

Children who received antineoplastic therapy, although they survive in increasing prevalence, still remain at risk of late adverse effects. Anticancer treatment is suggested as the background for dental anomalies.
The number and degree of dental disturbances seems to be dependent on the stage of tooth development at the start of chemotherapy $[15,17,18,22]$. Genetic variation modifying this relationship is still being considered, although no evidence substantiates this [3]. The authors of the current study found a strong correlation between the age at the time of therapy and the expected time of odontogenesis of teeth affected in almost $98 \%$ of cases. These observations are in agreement with the statement that up to $90 \%$ of cancer survivors may have oral sequelae of any type [1]. The authors agree with the opinion that there is a need to monitor patients after antineoplastic treatment $[13,19,23]$. It is recommended that patients with oncological history are radiologically examined no later than at the age of seven years.

\section{CONFLICT OF INTEREST}

The authors declare no potential conflicts of interest with respect to the research, authorship, and/or publication of this article.

\section{References}

1. Avsar A, Darka O, Pinarli G. Long-term effects of chemotherapy on caries formation, dental development and salivary factors in childhood cancer survivors. Oral Surg Oral Med Oral Pathol Oral Radiol Endod 2007; 104: 781-789.

2. Cameron AC, Widmer RP. Handbook of Pediatric Dentistry. $3^{\text {rd }}$ ed. Mosby Elsevier, 2008; 458-459.

3. Clemens E, van der Kooi ALF, Broer L, et al. The influence of genetic variation on late toxicities in childhood cancer survivors: a review. Crit Rev Oncol Hematol 2018; 126: 154-167.

4. Cubukcu CE, Sevinir B, Ercan I. Disturbed dental development of permanent teeth in children with solid tumors and lymphomas. Pediatr Blood Cancer 2012; 58: 80-84.

5. Dahllof G. Craniofacial growth in children treated for malignant diseases. Acta Odontol Scand 1998; 56: 378-382.

6. Gatta G, Botta L, Rossi S, et al. Childhood cancer survival in Europe 1999-2007: results of EUROCARE-5 - a population-based study. Lancet Oncol 2014; 15: 35-47.

7. Gawade PL, Hudson MM, Kaste SC, et al. A systematic review of dental late effects in survivors of childhood cancer. Pediatr Blood Cancer 2014; 61: 407-416.

8. Geenen MM, Cardous-Ubbink MC, Kremer MC, et al. Medical assessment of adverse health outcomes in long-term survivors of RC childhood cancer. J Am Med Assoc 2007; 297: 2705-2715.

9. Hölttä P, Alaluusua S, Saarinen-Pihkala UM, et al. Agenesis and microdontia of permanent teeth as late adverse effects after stem cell transplantation in young children. Cancer 2005; 103: 181-190.

10. Hölttä P, Alaluusua S, Saarinen-Pihcala UM, Wolf J, Nyström M, Hovi L. Long-term adverse effects on dentition in children with high-dose chemotherapy and autologous stem cell transplantation with or without total body irradiation. Bone Marrow Transplant 2002; 29: 121-127.

11. Kang CM, Hahn SM, Kim HS, et al. Clinical risk factors influencing dental developmental disturbances in childhood cancer survivors. Cancer Res Treat 2018; 50: 926-935.

12. Kaste SC, Hopkins KP, Bowman LC, Santana VM. Dental abnormalities in children treated for neuroblastoma. Med Pediatr Oncol 1998; 30: 22-27.

13. Kaste SC, Hopkins KP, Jones D. Dental abnormalities in children treated for acute lymphoblastic leukemia. Leukemia 1997; 11: 792-796. 
14. Krasuska-Sławińska E, Brożyna A, Dembowska-Bagińska B, Olczak-Kowalczyk D. Antineoplastic chemotherapy and congenital tooth abnormalities in children and adolescents. Contemp Oncol 2016; 20: 394-401.

15. Lyaruu DM, van Duin MA, Bervoets TJM, Wöltgens JH, Bronckers AL. Effects of actinomycin D on developing hamster molar tooth germs in vitro. Eur J Oral Sci 1997; 105: 52-58.

16. Macleod RI, Welbury RR, Soames JV. Effects of cytotoxic chemotherapy on dental development. J R Soc Med 1987; 80: 207-209.

17. Maguire A, Craft AW, Evans RGB, et al. The long-term effects of treatment on the dental condition of children surviving malignant disease. Cancer 1987; 60: 2570-2575.

18. Marec-Berard P, Azzi D, Chaux-Bodard AG, Lagrange H, Gourmet R, Bergeron C. Long-term effects of chemotherapy on dental status in children treated for nephroblastoma. Pediatr Hematol Oncol 2005; 22: 581-588.

19. Nasman M, Forsberg CM, Dahllof G. Long-term dental development in children after treatment for malignant disease. Eur J Orthod 1997; 19: 151-159.

20. Oğuz A, Cetiner S, Karadeniz C, Alpaslan G, Alpaslan C, Pinarli G. Long-term effects of chemotherapy on orodental structures in children with non-Hodgkin's lymphoma. Eur J Oral Sci 2004; 112: 8-11.

21. Pedersen LB, Clausen N, Schroder H, et al. Microdontia and hypodontia of premolars and permanent molars in childhood cancer survivors after chemotherapy. Int J Paediatr Dent 2012; 22: 239-243.

22. Proc P, Szczepańska J, Skiba A, Zubowska M, Fendler W, Młynarski W. Dental anomalies as late adverse effect among young children treated for cancer. Cancer Res Treat 2016; 48: 658-667.

23. Remmers D, Bokkerink JPM, Katsaros C. Microdontia after chemotherapy in a child treated for neuroblastoma. Orthod Craniofacial Res 2006; 9: 206-210.

24. Wilberg P, Kanellopoulos A, Ruud E, Hjermstad MJ, Fossa SD, Brokstad Herlofson B. Dental abnormalities after chemotherapy in long-term survivors of childhood acute lymphoblastic leukemia 7-40 years after diagnosis. Support Care Cancer 2016; 24: 1497-1506. 